\title{
SIGNIFICADOS DA DIDÁTICA COMO DISCIPLINA ESCOLAR NOS MANUAIS DE DIDÁTICA GERAL
}

\author{
MEANINGS OF DIDACTICS AS SCHOOL SUBJECT IN THE GENERAL DIDACTICS \\ MANUALS
}

\begin{abstract}
SIGNIFICADOS DE LA DIDÁCTICA COMO DISCIPLINA ESCOLAR EN LOS MANUALES DE DIDÁCTICA GENERAL
\end{abstract}

Léia de Cássia Fernandes Hegeto*

Tânia Maria F. Braga Garcia*

\begin{abstract}
Resumo: Este artigo apresenta resultados de pesquisa em que se analisaram configurações da Didática como disciplina escolar, tomando como material empírico manuais de Didática Geral publicados no Brasil a partir de 1980, conceitualmente entendidos como elementos visíveis do código disciplinar. A pesquisa foi desenvolvida em duas etapas: na primeira etapa, foram localizados dezoito manuais de Didática caracterizados como obras produzidas para ensinar o professor a ensinar; na segunda etapa, foram selecionados para análise nove destes manuais, três de cada década (1980, 1990, 2000). As análises selecionadas para apresentação neste artigo referem-se particularmente aos elementos relacionados a duas categorias analíticas, o conceito de Didática e os temas apresentados como corpo de conhecimentos da disciplina. Os resultados apontaram que os debates acadêmicos no campo da Didática resultaram na focalização do objeto da disciplina em torno do ensino e dos elementos da ação docente, ressignificando suas finalidades. O código disciplinar da Didática expresso nos manuais, no período analisado, pode ser caracterizado como o de reaproximação dos seus conteúdos e finalidades com o espaço da sala de aula e com o ensino, sem desconsiderar outras dimensões que envolvem o trabalho docente.
\end{abstract}

Palavras-chave: Didática Geral. Manuais Escolares. Manuais de Didática. Código Disciplinar.

Abstract: This paper presents the results of a research which analyzed some aspects of Didactics as a school course. Manuals of general didactics published in Brazil from 1980 onwards were used as empirical material, conceptually understood as visible elements of the disciplinary code. The research was developed in two phases: the first one identified eighteen didactics manuals characterized as books on how to teach the teacher to teach; the second phase selected nine of these manuals, three from each decade $(1980,1990,2000)$. The studies presented in this article refer to the elements of two categories of analysis in particular: the concept of Didactics and the themes considered as the body of knowledge of the course. The results pointed out that the academic debates in the field of Didactics came as a consequence of focusing the course's object on teaching and its elements, signifying their purposes. The Didactics disciplinary code expressed in the manuals of the period studied can be characterized as

*Doutora em Educação pela Universidade Federal do Paraná. Bolsista CAPES (2010-2013). Email: leiahegeto@ hotmail.com

${ }^{* *}$ Doutora em Educação pela Universidade de São Paulo. Professora da Universidade Federal do Paraná. Bolsista do Conselho Nacional de Desenvolvimento Científico e Tecnológico (CNPq). Email: taniabraga@pq.cnpq.br 
the approximation of contents and purposes with the classrooms and teaching, without disregarding the other dimensions involved in the professors' work.

Keywords: General Didactics. Textbooks. Didactics Textbooks. Disciplinary Code.

Resumen: Este artículo presenta resultados de pesquisa en que se analizaron configuraciones de la Didáctica como disciplina escolar, tomando como material empírico manuales de Didáctica General publicados en Brasil a partir de 1980, conceptualmente entendidos como elementos visibles del código disciplinar. La pesquisa fue desarrollada en dos etapas: en la primera etapa, fueron localizados dieciocho manuales de Didáctica caracterizados como obras producidas para enseñar el profesor a enseñar; en la segunda etapa, fueron seleccionados para análisis nueve de estos manuales, tres de cada década (1980, 1990, 2000). Los análisis seleccionados para presentación en este artículo se refieren particularmente a los elementos relacionados a dos categorías analíticas, el concepto de Didáctica y los temas presentados como cuerpo de conocimientos de la disciplina. Los resultados apuntaron que los debates académicos en el campo de la Didáctica resultaron en la focalización del objeto de la disciplina en torno de la enseñanza y de los elementos de la acción docente, resignificando sus finalidades. El código disciplinar de la Didáctica expreso en los manuales, en el período analizado, puede ser caracterizado como el de reaproximación de sus contenidos y finalidades con el espacio del salón de clase y con la enseñanza, sin desconsiderar otras dimensiones que involucran el trabajo docente.

Palabras-clave: Didáctica General. Manuales Escolares. Manuales de Didáctica. Código Disciplinar.

\section{Introdução}

As sucessivas reedições de alguns manuais de Didática Geral ao longo dos últimos trinta anos e a oferta de novos títulos publicados por editoras comerciais mais recentemente motivaram a realização de pesquisas sobre esses manuais no âmbito do Núcleo de Pesquisa em Publicações Didáticas, ligado ao Programa de Pós-Graduação em Educação da Universidade Federal do Paraná.

Além da constatação sobre a permanência dessas obras no mercado, o tema dos manuais de Didática Geral mostra-se instigante por outros motivos. Um deles está relacionado ao fato de que, embora frequentemente criticados em espaços acadêmicos e pouco recomendados para leitura ou consulta por especialistas, alguns desses manuais são sugeridos em referências para concursos e são incluídos, também, como bibliografia em cursos de formação de professores.
Entende-se que a permanência desse tipo de manual na cultura escolar está relacionada à natureza de sua finalidade: ensinar a ensinar - expressão que dá título ao livro de Afrânio Peixoto (1930) e se repete em publicações mais recentes, como o livro organizado por Amélia Domingos de Castro e Ana Maria Pessoa de Carvalho (2001). Nesse sentido, tais manuais expressam, com diferentes abordagens e a partir de concepções diferenciadas, elementos que constituem a Didática enquanto uma disciplina voltada à formação de professores.

Do ponto de vista teórico, portanto, o conceito de código disciplinar usado por Cuesta Fernandez (1998), para estudar a disciplina de História, e o usado por Schmidt (2011) e Urban (2009), para o caso da Didática da História, aponta possibilidades de discutir a configuração da Didática como disciplina escolar por meio da análise dos manuais produzidos, de forma geral, para o ensino dessa disciplina ou a partir dela. 
É com esse escopo que foram realizadas investigações relatadas por Garcia (2006; 2007; 2010), por Garcia e Hegeto (2011), por Hegeto e Garcia (2013) e por Hegeto (2014). Localizando, catalogando e analisando manuais de Didática Geral que circularam no Brasil desde as primeiras décadas do século XIX, tem sido possível problematizar e conhecer elementos constitutivos da disciplina, de forma complementar a outros tipos de investigação que usam outras fontes empíricas, como os programas, ementas e documentos legais.

O objetivo deste artigo é, portanto, apresentar elementos teóricos e metodológicos que sustentam as investigações realizadas, com destaque aos resultados da análise de manuais publicados a partir da década de 1980, na esteira do movimento de renovação dos debates no campo da Didática com o objetivo, segundo Candau (1984, p. 21) de "superação de uma Didática exclusivamente instrumental e a construção de uma Didática fundamental”.

O texto está organizado de forma a apresentar inicialmente algumas características da disciplina nos últimos trinta anos, selecionadas em função das possíveis relações com o tema dos manuais. Em seguida, foram apontados os elementos constitutivos do conceito de “código disciplinar” que contribuem para sustentar a análise da Didática pelo que os manuais expressam. Finalmente, apresentam-se os procedimentos relacionados à localização e seleção dos manuais e resultados da investigação, em particular quanto ao significado da Didática para os autores e quanto aos conteúdos e temas privilegiados por eles.

\section{Problematizações sobre a Didática como disciplina escolar nas últimas décadas}

Apesar de ser uma disciplina “clássica”, obrigatória em grande parte dos cursos de formação de professores, a Didática vem perdendo espaço no currículo, pelo menos com o nome Didática Geral, como tem sido apontado por autores como Martins e Romanowski (2010), Gatti e Nunes (2009), entre outros estudos. Além da preocupação com a perda de espaço, aponta-se também uma possível dispersão e diversificação quanto ao conteúdo e objeto de ensino (CANDAU, 2009).

Segundo Gatti e Nunes (2009), a forma como a disciplina aparece nos currículos aponta para a existência de vários entendimentos para a palavra Didática. "Há disciplinas nomeadas Didática, disciplinas identificadas como Didática Geral e disciplinas identificadas como Didática do Ensino de Língua Portuguesa, Matemática, História, Geografia, Artes, Ciências e Educação Física” (GATTI et al, 2008, p.41). Assim, o campo abrangido ultrapassa o âmbito da Didática Geral para estender-se também ao domínio das metodologias de ensino específicas.

Em relação aos variados nomes que tem recebido a disciplina de Didática, Castro (1991) destaca que o fenômeno, que não é novo, pode estar relacionado a um equívoco que identifica a disciplina com o seu conteúdo:

Novos modos de interpretar o fenômeno Ensino, orientações práticas derivadas de teorias diferentes, desencadeiam, parece-me, a necessidade de encontrar um novo nome para um procedimento e uma reflexão que se alteraram: se chamam o ensino de “direção da aprendizagem”, exigem nova denominação para a disciplina que dele se ocupa. Os adjetivos que são acrescentados à Didática parecem periodicamente cumprir esse papel de alterá-la ao sabor do seu conteúdo. (CASTRO, 1991, p. 22)

Essa precisa observação da autora remete à necessidade de análise atenta dos pesquisadores interessados em compreender as configurações da disciplina. Também nos 
títulos de manuais didáticos podem ser detectadas, de forma indiciária, objetivações do fenômeno apontado por Castro, como se observa: Didática Mínima (GRISI, 1952) em contraposição à Didática Magna de Comenius, a Didática da Escola Nova (AGUAYO, 1970), para se contrapor à concepção tradicional de ensino, ou ainda a Didática do Ensino a Distância (PETERS, 2006) na diferenciação com o ensino presencial.

A problemática dos adjetivos atribuídos ao nome da disciplina Didática e quanto ao modo como a disciplina se faz (ou não) presente no currículo em determinados períodos afeta a proposição dos conteúdos, que se modificam, então, para atender as demandas de cada tempo. Assim, a análise do conteúdo de uma disciplina estará obrigatoriamente submetida à análise dos contextos históricos específicos nos quais sua presença no currículo é reconhecida como necessária.

No caso da Didática, os embates decorrentes de diferentes concepções na abordagem dos conteúdos têm sido apontados por autores como Libâneo (2010), que enfatiza a persistência de um caráter instrumental na disciplina. Por outro lado, André e Cruz (2012) afirmam que o ensino de Didática parece superar a tendência instrumental, embora constatem uma dificuldade na focalização de quais seriam os elementos fundamentais a serem ensinados na disciplina.

Marin, Penna e Rodrigues (2012, p. 67), ao tratarem especificamente do ensino superior, destacam que são muitos os conhecimentos que fazem parte do universo complexo que é o campo pedagógico. Assim, de acordo com as autoras, muitos professores acabam abordando conteúdos de outros campos de conhecimento por trazerem contribuições à formação do professor, ocasionando ao discurso didático atual uma desorientação quanto às suas prioridades e temáticas.
Conhecimentos sobre as condições sociais dos alunos, seu desenvolvimento e condições para a aprendizagem, por exemplo, são considerados como necessários, mas não como conteúdos de Didática.

E quais seriam esses conteúdos? Com a finalidade de contribuir com a prática em sala de aula, Marin, Penna e Rodrigues (2012) sugerem que sejam abordadas questões como: exigências de cada aula com seus conteúdos; procedimentos diversificados; recursos materiais; o planejamento; formas de relacionamento com os alunos, formas de avaliação e relações com a organização do trabalho pedagógico escolar em que estão inseridos.

Historicizando a questão, relembra-se a perspectiva apontada por Candau (1993) ao final da década de 1980 quanto ao objeto da Didática Geral. O estudo do processo de ensino e, nele, a compreensão da aula como fenômeno especificamente didático foram problematizados e traduzidos, naquele momento, pela ideia de que o objeto da Didática seriam as práticas pedagógicas e seus estruturantes (CANDAU, 1993, p.38). A partir de então, ao longo das últimas décadas, a questão do objeto da disciplina tem sido posta em debate e, por consequência, também os conteúdos que devem compor o espectro dos seus programas nos cursos de formação de professores.

É necessário reconhecer a complexidade da questão. Os conteúdos chamados “clássicos” foram abordados, ao longo do período, tanto em alguns programas quanto em alguns manuais didáticos. Criticados pela abordagem tecnicista que marcou esses temas por décadas, constata-se que retornam agora ao centro de proposições, com ressalvas como as apresentadas por Marin, Penna e Rodrigues (2012, p.72): "mantê-los por serem de fato centrais, porém operar com eles de forma descritiva, analítica, crítica”. Essa autora acrescenta ainda que não cabem prescrições, mas 
sim compreensões sobre esses conteúdos de modo a estabelecer relações com os demais conhecimentos pedagógicos. Para as autoras é preciso retomar o papel central conferido à Didática voltando-se a:

[...] algo que lhe é peculiar, - o modo de agir para ensinar - ou seja, a técnica, sim, como parcela da cultura em geral e da cultura escolar em particular, portanto não despregada de todo ambiente organizativo que lhe dá contexto e, neste, não apenas o currículo estritamente pensado (MARIN, 2008, p. 10).

Essas problematizações foram retomadas, aqui, para justificar a proposta de continuar investigando a Didática enquanto uma disciplina de formação de professores, que tem sido caracterizada e conceituada por pesquisadores do campo, entre outras formas, como o estudo do ensino (VEIGA, 2006), espaço de embates entre uma perspectiva teórica e outra prática (MARTINS, 1989), ou ainda a partir da noção da multidimensionalidade do processo de ensino e aprendizagem a sustentar uma didática fundamental (CANDAU, 1984).

Apesar da existência de estudos significativos sobre os manuais didáticos, sua análise para a compreensão das configurações da própria disciplina é pouco frequente. Assim, essa opção tem orientado as pesquisas do NPPD/UFPR com a intenção de contribuir, ao lado de outros estudos, para conhecer elementos constitutivos da Didática Geral enquanto uma disciplina, tradicionalmente presente nos currículos de formação de professores.

Nesse sentido, diante de tais preocupações, buscou-se analisar a Didática como disciplina escolar no Brasil nas últimas três décadas, a partir de uma abordagem específica, ou seja, a partir da análise de manuais de Didática Geral entendidos como elementos do código disciplinar (CUESTA FERNANDEZ, 1998). Tomados como "elementos visíveis" desse código, podem ser tomados como expressões do código disciplinar da Didática Geral, pois esses livros sugerem e legitimam determinados conteúdos, regras, normas, ideais e discursos relacionados ao ensino.

Portanto, defende-se a centralidade que os manuais de Didática Geral assumiram na construção da trajetória da Didática como disciplina escolar, destacando que, ao mesmo tempo em que contribuíram para a sua organização, também se organizaram a partir dela. Considera-se a existência da Didática Geral como uma disciplina que é produzida no âmbito de um campo científico ${ }^{1}$ no qual os agentes produzem e fazem circular um tipo de conhecimento específico (HEGETO, 2014).

\section{Os manuais como elementos visíveis do código disciplinar: possibilidades para a pesquisa}

O estudo dos livros escolares - também chamados de manuais escolares, manuais didáticos ou livros didáticos - constituiu-se, nas últimas décadas, como um campo consolidado no âmbito acadêmico, cuja complexidade foi reconhecida a partir de trabalhos como os de Choppin (2001). Desde sua conceituação, passando pelas abordagens possíveis desse objeto e as dificuldades em mapear a produção de pesquisas ao redor do mundo, o manual escolar se apresenta aos pesquisadores como um desafio, pela sua reconhecida complexidade.

Ao examinar as relações dos livros escolares com a configuração das disciplinas,

\footnotetext{
${ }^{1}$ Quanto ao conceito de campo científico, o define como o lugar de disputas pela autoridade científica, resultante da combinação entre competência técnica e poder político. O campo é considerado por esse autor tanto como um 'campo de forças', que constrange os agentes nele inseridos, quanto um 'campo de lutas', no qual os agentes atuam mantendo suas posições ou modificando sua estrutura (BOURDIEU, 1996).
} 
Cuesta Fernandez (1997) afirma que os manuais escolares são elementos visíveis do código disciplinar, uma vez que ordenam os conteúdos considerados necessários em cada período, contribuindo para a organização das disciplinas. O código disciplinar deve ser entendido como uma tradição social configurada historicamente, que legitima a função educativa que deve cumprir cada disciplina escolar e que regula a prática do seu ensino. Nessa perspectiva, o estudo de uma disciplina escolar pode apoiar-se nos elementos do seu código disciplinar, sejam os visíveis - como as normatizações, os programas e os anuais -, sejam os elementos invisíveis - como as práticas escolares.

No caso da pesquisa aqui relatada, o interesse voltou-se aos manuais que são destinados à formação de professores. No Brasil, eles foram difundidos durante todo o século $X X$. Segundo Bufrem, Schmidt e Garcia (2006), o tripé difusão da escola, formação de professores e renovação pedagógica estimulou a produção de livros destinados à formação de professores. "Estas publicações consolidar-se-ão como documentos importantes para orientação das práticas pedagógicas escolares, de modo geral, e de cada disciplina, em particular” (BUFREM, SCHMIDT, GARCIA, 2006, p.124.125).

Estes livros foram usados inicialmente por normalistas ${ }^{2}$, que frequentavam os antigos cursos normais preparando-se para serem professores; posteriormente se mantiveram fazendo parte das leituras promovidas pela escola com os futuros professores e foram escritos para transmitir determinados saberes, ordenando-os no interior de determinada disciplina do currículo (CORREIA, 2000). De acordo com esse autor, os manuais didáticos

\footnotetext{
${ }^{2}$ A formação de professores na primeira metade do século XX esteve vinculada à existência das escolas normais de nível médio, que continuaram existindo no país até a década de 1990.
}

congregam aspectos teóricos e orientações para a condução da prática docente, articulando num mesmo impresso o campo doutrinário da pedagogia, as determinações legais e os procedimentos necessários para sua consecução.

Manuais que apresentam esses conhecimentos têm como objetivo divulgar formas de ensinar, ou seja, orientam os professores sobre como agir em sala de aula, sobre a postura que devem ter, sobre práticas e metodologias a utilizar, produzindo o que foi chamado por Silva (2006) de "gramática do magistério". Contudo, segundo a mesma autora, pesquisas sobre os manuais para professores são, ainda, relativamente escassas (SILVA, 2008, p. 117).

Guereña, Ossenbach e Pozo (2005), reconhecendo também a lacuna, acompanham a percepção de outros autores quanto ao fato de que o estudo sistemático dos manuais vem ganhando espaço, e sua relevância está justificada na possibilidade de ampliar a compreensão sobre os processos de profissionalização dos professores ao longo do tempo.

Uma distinção foi apontada por Bufrem, Schmidt e Garcia (2006) quanto ao fato de que uma parte desses manuais apresenta uma gama de saberes que podem ser incluídos nos saberes e práticas que são próprios da Didática das disciplinas. O conteúdo destes manuais pode ser apreendido, então, como um conjunto de saberes que exercem a "função de mediação entre o conhecimento científico específico e os modos de ensiná-lo na sala de aula” (BUFREM, SCHMIDT, GARCIA, 2006, p.123).

Entre os diferentes tipos de manuais destinados aos professores, aqui se destacam aqueles voltados especificamente a ensinar a ensinar. Eles podem ser a princípio categorizados em dois grupos: os Manuais de Didática Geral e os de Didática específica. Segundo Garcia e Nascimento (2009), os 
antigos manuais de Didática Geral tinham como objetivo estabelecer "regras para bem ensinar” e neles apresentava-se uma parte geral - princípios, regras e métodos para o trabalho nas aulas - e às vezes uma segunda parte em que mostrava como aplicar tais ideias nas disciplinas específicas. No início do século, alguns são identificados como Tratados de Metodologia.

Bufrem, Schmidt e Garcia (2006) e Garcia (2006) examinam a questão dos manuais para professores a partir do conceito de código disciplinar e chamam a atenção para o fato de que as análises realizadas, em especial no âmbito da Didática da História e da Didática Geral, têm evidenciado a necessidade de organizar acervos e desenvolver pesquisas que buscam relações entre a temática dos manuais didáticos e a formação de professores, tomando os manuais como fontes para entender a configuração das Didáticas como disciplinas escolares.

Quanto aos manuais de Didática Geral, eles se mantiveram presentes nos cursos de formação de professores, continuam a ser utilizados como leitura para professores em formação, circulam em livrarias, bibliotecas, acervos físicos e virtuais e, no caso de alguns, continuam sendo sucessivamente reimpressos. Apesar disso, deve-se dizer também que as pesquisas sobre os manuais de Didática Geral são poucas, o que justificou esta pesquisa cujos procedimentos e resultados serão apresentados nas próximas seções. A análise desses manuais pode evidenciar elementos que constituíram a Didática como disciplina escolar ao longo do século e pode contribuir para compreender sua configuração atual, seu significado, suas questões e desafios.

\section{A pesquisa empírica: constituição do corpus documental e procedimentos}

Para a constituição do acervo e do corpus documental, definiu-se como demarcação temporal o período de 1980 a 2013, em função das discussões no campo científico da Didática na primeira metade da década de 1980, que promoveram mudanças no entendimento sobre o significado da Didática para a formação de professores, opondo-se à perspectiva instrumental e tecnicista que a caracterizava. Portanto, a opção foi por examinar os manuais produzidos a partir desse momento histórico, para compreender se eles expressaram e expressam as transformações e, por outro lado, se contribuíram para mudanças na configuração dessa disciplina escolar.

$\mathrm{Na}$ etapa inicial, realizou-se pesquisa empírica para identificação, seleção e categorização de manuais em circulação. Na busca em bases virtuais para localizar produções sobre a Didática, ao lado de artigos e trabalhos científicos, foram identificados dois grupos de obras: a) Livros sobre a Didática como disciplina ou campo de conhecimento, obras que têm a finalidade principal de divulgar a produção acadêmica sobre o tema; b) Manuais de Didática, destinados aos professores, cuja finalidade principal é a orientação para o ensino, ou seja, ensinar a ensinar.

A opção em analisar manuais de Didática está sustentada em alguns motivos: esses manuais cumprem um determinado papel na formação do professor, são utilizados nos cursos de formação de professores, alguns têm sido sucessivamente reimpressos - indício de que continuam sendo utilizados e comprados - e têm sido indicados em bibliografias para concursos públicos para professores. O levantamento inicial resultou na identificação de quarenta e oito obras. Dentre elas, foi possível categorizar dezoito manuais cuja finalidade é ensinar professores a ensinar. A etapa 
seguinte consistiu em uma leitura flutuante das obras e a seleção de nove manuais para análise, três de cada década, um publicado ao início, um no meio e um ao final da década, conforme indicado a seguir:

Quadro 1: Manuais de Didática Geral analisados

\begin{tabular}{|l|l|l|l|l|}
\hline MANUAL & TÍTULO & AUTOR & ANO & EDITORA \\
\hline Manual 1 & Didática Geral & Claudino Piletti & 1982 & ÁTICA \\
\hline Manual 2 & $\begin{array}{l}\text { Didática Geral: Fundamentos } \\
\text { Planejamento, Metodologia e Avaliação }\end{array}$ & José do Prado Martins & 1985 & ATLAS \\
\hline Manual 3 & Didática teórica Didática pratica & Pura Lucia O. Martins & 1989 & LOYOLA \\
\hline Manual 4 & Didática & Jose Libâneo & 1992 & CORTEZ \\
\hline Manual 5 & Curso de Didática Geral & Regina Célia C. Haydt & 1994 & ÁTICO \\
\hline Manual 6 & Didática Geral: um olhar para o futuro & Maria Raineldes Tosi & 1996 & ALINEA \\
\hline Manual 7 & $\begin{array}{l}\text { Ensinar a Ensinar: Didática para a } \\
\text { escola Fundamental e Média. }\end{array}$ & $\begin{array}{l}\text { Amélia D. de Castro/ Ana } \\
\text { Maria P Carvalho (orgs) }\end{array}$ & 2001 & $\begin{array}{l}\text { THOMPSON } \\
\text { PIONEIRA }\end{array}$ \\
\hline Manual 8 & Lições de Didática. & Ilma Passos A. Veiga (org.) & 2006 & PAPIRUS \\
\hline Manual 9 & $\begin{array}{l}\text { Didática e docência: aprendendo a } \\
\text { profissão. }\end{array}$ & Isabel Maria S. de Farias (org.) & 2009 & $\begin{array}{l}\text { LIBER } \\
\text { LIVROS }\end{array}$ \\
\hline
\end{tabular}

Fonte: HEGETO, 2014.

As obras foram analisadas em seu conteúdo, com apoio em Franco (2005) e Bardin (2009). Considerando-se o objetivo de compreender as configurações da Didática como disciplina escolar a partir dos manuais, as categorias estruturadoras da análise foram definidas em torno dos seguintes elementos: a) $\mathrm{O}$ conceito de Didática apresentado explícita ou implicitamente nos manuais; b) As temáticas abordadas nos manuais; c) As atividades de ensino propostas para orientar a aprendizagem dos alunos.

As análises possibilitaram evidenciar os elementos do código disciplinar da Didática e, nos limites deste texto, foram privilegiados resultados obtidos a partir das duas primeiras categorias, os quais serão apresentados a seguir.

\section{Significados da Didática Geral: finalidades e temas nos manuais analisados}

Em trabalho avaliativo sobre o conhecimento didático, André (2008) problematiza o lugar que a Didática tem ocupado nas pesquisas educacionais. Os resultados da pesquisa indicam que, lamentavelmente, o ensino da Didática que era um forte objeto de estudo "nos primeiros tempos do GT [Grupo de Trabalho da ANPED], desapareceu das pesquisas” (ANDRÉ, 2008, p. 499). Pode-se acrescentar um elemento a esse debate, lembrando que a Didática não aparece na lista de temas de pesquisa dos programas de pós-graduação em educação da região sul, denominado “Anpedinha”, no ano de 2014.

Por outro lado, em obras de outros autores, há a afirmação de que a Didática ainda está em questão (FRANCO; FUSARI, 2010), sugerindo a possibilidade de um movimento similar ao que ocorreu na década de 1980, que 
recoloca em pauta questões relacionadas ao campo de produção dos conhecimentos didáticos e ao lugar que a disciplina tem ocupado, seja nas pesquisas seja nos currículos para formação de professores.

Essas referências foram aqui escolhidas por serem indiciárias da problemática complexa que caracteriza a trajetória da Didática Geral como uma disciplina escolar, como destacado por Gatti et al (2008) e Martins e Romanovski (2010), que apontam controvérsias quanto à finalidade e objeto da disciplina, sua desvalorização e a diminuição em sua carga horária em cursos de Pedagogia e Licenciaturas e, inclusive, sua substituição por outras disciplinas.

Esses debates sobre o significado da disciplina podem ser enriquecidos pela análise dos manuais de Didática Geral que circulam desde a década de 1980 no país. O que esses manuais revelam sobre a trajetória da disciplina? Como a apresentam aos professores em formação? Que finalidades atribuem a esse conhecimento? Que temas são apresentados aos professores como conteúdo necessário a quem ensina? Que mudanças e permanências eles expressam?

\section{Conceituações sobre a Didática nos manuais analisados}

No que se refere ao conceito de Didática, verificou-se a tentativa de (re)definir a função e o papel da disciplina, evidenciando que os debates no campo científico ao longo das últimas décadas produziram efeitos nesses artefatos da cultura escolar. Alguns manuais apresentam uma unidade ou capítulo específico em que a conceituação é feita de forma explícita, como no manual 1 (1982), em que o autor propõe um capítulo denominado "Pedagogia e Didática”.
Outra obra, publicada na década de 1990, também apresenta tópicos específicos para discutir o conceito, entre os quais duas unidades denominadas "Educação escolar, Pedagogia e Didática” e “A Didática e a formação profissional do professor”. Nesta, a presença da relação com o conceito de formação profissional de professores já expressa a incorporação dos debates da sociologia do trabalho no âmbito do discurso pedagógico. As discussões no país foram influenciadas por autores, como António Nóvoa (1995), organizador de obra denominada Profissão Professor, publicada em 1992.

Destaca-se uma perspectiva diferenciada para apresentar o conceito de Didática que se encontra no manual 7 , organizado por Castro e Carvalho (2001) e publicado no início dos anos 2000. Na primeira parte do livro, intitulada Reflexões sobre a Didática, autores discutem o objeto da disciplina - o ensino - e tratam de algumas relações entre a Didática e a Escola, o Currículo e a Aula. Essa organização reflete os debates no campo do currículo desde a década anterior, que recolocou questões ao campo da Didática, expressos na obra como um espaço de reflexão que antecede a apresentação da segunda parte, intitulada “A Didática em ação”.

Com esses destaques, pode-se exemplificar a diversidade de formas pelas quais os autores dos manuais selecionados organizaram a apresentação do seu conceito de Didática. Ao mesmo tempo, pode-se compreender que os manuais expressam, nesse aspecto, algumas transformações que ocorreram no âmbito educativo, pedagógico e didático, recolocando questões a partir de novas relações entre a disciplina e outros campos de conhecimento. Duas subcategorias foram definidas para organizar os elementos constitutivos do conceito de Didática nos manuais analisados, como se apresenta a seguir. 
Didática, o campo de produção científica e a disciplina escolar: explicitando relações, desfazendo equívocos.

Uma das constatações feitas ao analisar os manuais selecionados refere-se ao fato de que, ao longo das últimas décadas, esses artefatos da cultura escolar foram gradativamente - ainda que de forma não linear - apresentando elementos que contribuem para esclarecer uma problemática que foi apontada por Castro (1991) quanto ao fato de que o conteúdo de uma disciplina não deve ser confundido com o conteúdo que se produz a respeito dessa disciplina, enquanto atividade científica e de meta-análise.

Obviamente, as duas instâncias guardam relações, mas essas questões acabaram por gerar dificuldades, ao longo das últimas décadas, na definição dos conteúdos que um professor deveria trabalhar com seus alunos em aulas de Didática. No caso dos manuais, em algumas situações observou-se que os conteúdos seriam mais adequadamente denominados de conteúdos sobre a Didática, e não conteúdos de Didática.

Essa constatação teórica e empírica levou à decisão, explicada na seção sobre os procedimentos de pesquisa, de distinguir dois tipos de manual, escolhendo para análise aqueles que foram considerados "manuais de Didática”, ou seja, livros que se organizaram para apresentar, aos professores, conteúdos necessários ao exercício da ação docente, do ponto de vista da Didática Geral.

Nesse sentido, os manuais selecionados fornecem evidências de que a maior parte dos autores, ao lado do reconhecimento da existência de um campo de produção científica que investiga as questões sobre o ensino, também apresentou seus leitores a um conjunto de conhecimentos considerados necessários ao exercício da profissão docente, quanto ao planejamento, desenvolvimento e avaliação do ensino.

Assim a Didática foi identificada pelos autores como campo de conhecimento, mas também como uma disciplina escolar, que tem objetivos próprios. Dos nove manuais examinados, seis dizem explicitamente que ela é uma disciplina. Destacam-se as citações:

A didática é uma disciplina técnica e que tem como objeto específico a técnica de ensino (direção técnica da aprendizagem). A didática, portanto, estuda a técnica de ensino em todos os seus aspectos práticos e operacionais podendo ser definida como: "A técnica de estimular, dirigir e encaminhar, no decurso da aprendizagem, a formação do homem (Aguayo)" (PILETTI, 1982, p.42).

A Didática como disciplina que terá de compreender o processo de ensino em suas múltiplas determinações para, intervindo nele, transformá-lo, por meio de propostas concretas de ação, tendo em vista um posicionamento político claro e definido, deixando de ser uma disciplina meramente instrumental (MARTINS, 1989, p.14).

Embora com diferentes perspectivas e abordagens, os dois autores reconhecem a existência de uma disciplina escolar que tem especificidades, e cujo objeto centraliza-se em torno do processo de ensino, que necessita ser compreendido. De forma ampla, essa compreensão também está presente nos demais manuais, permitindo afirmar que, enquanto elementos visíveis do código disciplinar, eles evidenciam a existência e o reconhecimento da disciplina, contribuindo então para desfazer alguns equívocos que circularam e circulam no campo educacional.

Ao lado de elementos como a legislação educacional, programas e ementas, materiais que têm sido objeto de outras pesquisas, 
os manuais evidenciam a existência da disciplina e um consenso quanto ao seu objeto - o ensino - a partir da segunda metade da década de 1980; poder-se-ia falar que, nesse aspecto, a disciplina encontra-se em um período de estabilidade desse elemento em seu código disciplinar.

Natureza do conhecimento ensinado: do tecnicismo à multidimensionalidade

Como se apontou anteriormente, a partir da década de 1980, registrou-se um forte consenso em torno da necessidade de rever a ênfase nas técnicas e procedimentos que caracterizava a Didática enquanto uma disciplina escolar. Essas transformações foram constatadas, de alguma forma, nos manuais analisados. Para as autoras de um dos manuais, a Didática é entendida como

[...] um conhecimento pedagógico fundamental à ação do professor e que extrapola o caráter aplicado. Seu estudo abrange a problematização, o entendimento e a sistematização de questões relacionadas à docência, articulando objetivos, conteúdos, metodologias, e avaliação do ensino a reflexão sobre a identidade profissional, a dimensão ética do trabalho do professor, os conhecimentos necessários a prática educativa, entre outras pautas (FARIAS, et al, 2009, p.18).

Observa-se neste fragmento, que o caráter instrumental e técnico que havia marcado as obras da década anterior, como evidenciado em diversos estudos sobre a disciplina (CANDAU, 1984) e sobre os manuais (GARCIA, 2006), foi substituído gradativamente por uma concepção que, sem deixar de considerar os elementos didáticos como planejamento, técnicas e procedimentos de ensino, sublinhou a reflexividade na ação didática e a natureza investigativa do conhecimento didático.

Os debates no campo científico sobre a necessidade de reflexão crítica sobre o processo de ensino e sobre a realidade social trouxeram transformações na disciplina. As discussões foram sistematizadas nos seminários realizados ao início da década e foram incorporadas de diferentes formas, pelos manuais. No livro 1, publicado ao início da década, já se encontra uma referência à necessidade de que o professor escolha as alternativas que considera mais adequadas, evidência de que a neutralidade das técnicas deixava de ser uma premissa: "No decorrer dos capítulos deste livro, além de apresentarmos uma série de alternativas para a atividade docente, apresentamos também alguns elementos de reflexão, para ajudar o professor a escolher as alternativas mais adequadas para cada situação” (PILETTI, 1982, Apresentação do livro).

O questionamento que teve início nos primeiros anos daquela década quanto ao caráter instrumental e mecanicista da Didática e, por consequência, sobre a necessidade de uma maior reflexão e consciência crítica entre os professores, desencadeou um processo de mudanças no entendimento da função da disciplina, que se expressa também nos manuais. Pode-se constatar em vários manuais a presença da ideia de multidimensionalidade como alternativa a uma visão exclusivamente técnica da disciplina.

Verificou-se em alguns manuais (3, 8 e 9) a preocupação em denunciar o aspecto instrumental na Didática, como se observa neste texto: “Entendemos ser necessário romper com a concepção tecnicista de aprendizagem que ainda sustenta nossas práticas de ensino. É preciso pautar nossa atividade docente na compreensão da aprendizagem como um ato coletivo e contínuo, ir além da ação metodológica restrita à exposição verbal 
e aos exercícios de fixação” (FARIAS et al, 2009, p.124). No manual 4 o autor reconhece que a formação do professor abrange duas dimensões: a formação teórico-científica e a formação técnico-prática "visando a preparação profissional específica para a docência”.

Também no manual 9 afirma-se a importância dos métodos e estratégias de ensino, que podem ser traduzidos como: "Um conjunto teórico constituído por pressupostos, princípios e procedimentos orientadores do trabalho pedagógico”. (FARIAS et al, 2009, p.138). Para essas autoras, a orientação no livro quanto à forma de utilização da exposição oral e dialogada segue uma sequência como: abertura do tema, síntese do assunto, socialização, contextualização, apresentação de situações problemas, exposição. Porém as autoras fornecem ao professor algumas orientações quanto ao emprego desta estratégia que requer “certos cuidados e atenção para com os objetivos e a sequência dos tópicos da exposição; o limite de tempo e os recursos auxiliares, a movimentação no espaço em que ocorre; a linguagem, o ritmo e a entonação de voz do expositor” (FARIAS et al. 2009, p.143).

Outro aspecto observado é o deslocamento do objeto da Didática da “direção da aprendizagem”, no início da década de 1980, para a “direção do ensino”. Deve-se lembrar de que a Psicologia havia exercido grande influência sobre as teorias educativas na primeira metade do século XX, e a aprendizagem havia se constituído como centro das discussões, especialmente na perspectiva da Escola Nova.

Foi possível localizar tal deslocamento na concepção expressa nos manuais analisados quanto ao objeto da Didática, centralizando o ensino e seus elementos. Mas, ao mesmo tempo, muitos autores colocaram em evidência que a aprendizagem é a finalidade dos processos de ensino. Esta posição corresponde, de alguma forma, aos pressupostos das diretrizes curriculares produzidas no país na década de 1990, de natureza construtivista, referenciados na Psicologia e que dão centralidade à aprendizagem como construção do conhecimento.

Verificou-se, portanto, quanto à categoria Conceito de Didática, que a partir de 1980 os manuais incorporaram, em diferentes medidas, os debates sobre a natureza do conhecimento escolar específico da disciplina, especialmente no que se refere à superação da perspectiva tecnicista/comportamentalista. Os manuais expressam de diferentes formas que o conhecimento da Didática exige uma visão de multidimensionalidade do processo de ensino. No entanto, foi observado em alguns manuais um alerta no sentido de que a dimensão técnica não fosse desconsiderada.

\section{Os temas a serem ensinados na Didática}

De acordo com Chervel (1990), o corpo de conhecimentos a ser ensinado é um elemento fundamental na constituição de uma disciplina escolar. Enquanto elementos visíveis do código disciplinar, os manuais revelam temas que constituem o corpo de conhecimento em dado período, permitindo ao pesquisador verificar permanências, mas também capturar movimentos de inclusão e exclusão de conteúdos, na relação com as transformações sociais daquele período.

\section{As temáticas clássicas}

A análise dos manuais apontou a permanência, com pequenas variações, das temáticas aqui denominadas de clássicas, relacionadas aos elementos do ensino - planejamento, objetivos, metodologia, relação professor-aluno e avaliação. Pode-se afirmar que essas temáticas se apresentaram como 
uma materialização do código disciplinar da Didática nesse período. Sabe-se, com apoio nos autores de referência, que a existência das temáticas em um livro está condicionada por vários fatores do âmbito social, da cultura escolar e da cultura da escola, como novas demandas da sociedade, os interesses e preferências do próprio autor, as definições editoriais, os aspectos comerciais, a aceitação pelos professores e a relevância social e acadêmica naquele momento histórico.

Verificou-se uma variação no que se refere à forma como esses temas aparecem nos manuais, ao longo das três últimas décadas. Enquanto os livros analisados da década de 1980 e 1990 trazem as temáticas nos títulos de capítulos - por exemplo, Capítulo 6: Objetivos -, os livros da década de 2000 evitam essa forma de apresentação, criando títulos como "Atividade de ensino como ação formadora”, em que o autor trata da organização do ensino abordando assuntos como "o modo como o conhecimento é adquirido” e "as finalidades do que se aprende" (MOURA, 2001, p.146).

Assim, o que se observou nos livros analisados é que, mesmo sem apresentar as temáticas clássicas nos títulos dos capítulos, os manuais de algum modo abordam e demonstram a importância de tais temáticas. Autores de relevância no campo científico da Didática reafirmam de diferentes formas a presença e a necessidade de retomada de temas clássicos, como destacado por Veiga (2010, p. 52) e Candau (2006).

Trata-se de uma decorrência dos debates e embates no campo científico, que após as discussões da década de 1980 e 1990 quanto aos pressupostos e fundamentos da Disciplina, apontavam a ausência - do ponto de vista da produção de conhecimento - dos grandes temas da disciplina. Nos manuais, contudo, esses temas não estiveram ausentes nas últimas três décadas, revelando uma permanência que se contrapôs a um discurso que exigia uma transformação radical na disciplina, gerando um equívoco que identificava os temas clássicos com sua abordagem tecnicista naquele momento.

Portanto, constatou-se que as temáticas, apesar das críticas e mudanças na nomenclatura, permaneceram nos manuais, apresentando-se transformadas, adaptadas ou ajustadas às demandas e pressões nesse período, coexistindo com as novas temáticas. Nesse sentido, o olhar para os manuais deve supor sempre o cuidado analítico de identificação dessas formas que dão novos conteúdos aos temas. Assim, eles são os mesmos, clássicos, mas também não os são.

\section{As novas temáticas}

Evidenciou-se que as novas temáticas encontradas nos manuais tiveram origem nos debates sociais, educacionais e curriculares. Elas mostram o desafio da disciplina quanto à necessidade de ampliação das questões tratadas, de diversificação e pluralidade de temáticas, ainda que sob o risco de uma perda de foco ou de uma dispersão, como já apontado.

Dentre os temas que passaram a ser tratados nos manuais de Didática, substituindo ou dividindo espaço com os temas clássicos, podem ser citados os temas da multiculturalidade e da interdisciplinaridade - que não são temas exclusivos da Didática, mas que se inserem no âmbito das questões tradadas pela disciplina. Além desses, nos dezoito manuais localizados podem ser citados os seguintes temas, encontrados nos sumários analisados: competências; professor reflexivo; identidade do professor; temas transversais; sistematização coletiva do conhecimento; tecnologia; informática; sociedade digital; ética; transposição didática; fracasso escolar; disciplina/ 
indisciplina; educação inclusiva; sexualidade; questões de gênero e raça; livro didático.

Das temáticas mencionadas, algumas derivam de novas concepções sobre a profissão docente, outras ganharam espaço a partir de problemáticas específicas do trabalho escolar e outras, ainda, remetem às conquistas decorrentes de lutas sociais e conquistas de direitos por grupos específicos, nas últimas décadas. Independentemente dos motivos que geraram esses novos temas, as análises mostraram como os manuais expressaram as mudanças ocorridas nos debates acadêmicos e sociais, evidenciando características do código disciplinar da Didática no período considerado.

\section{Considerações Finais}

Os resultados obtidos na análise permitem afirmar, no que se refere às características e elementos constituintes da disciplina de Didática a partir da década de 1980, que as transformações ocorridas na Didática enquanto campo científico - e que produziram transformações também nos manuais didáticos - resultaram em uma focalização mais clara do objeto da disciplina em torno do ensino e dos elementos da ação e da prática docente, ressignificando as finalidades da disciplina em torno de três eixos: a formação didática de professores em perspectiva multidimensional; a transformação do trabalho docente pela valorização da reflexão e da investigação; a compreensão ampliada dos elementos constitutivos do ensino que inclui, nas temáticas clássicas, dimensões e temas originados das demandas sociais.

Afirma-se que o código disciplinar da Didática, atualmente, se caracteriza por uma reaproximação dos conteúdos e finalidades da disciplina com o espaço da sala de aula e com os procedimentos de ensino, sem desconsiderar suas outras dimensões. Assim, ao mesmo tempo em que se observa a exclusão da disciplina em currículos de formação de professores, a pesquisa sobre os manuais contribuiu para estimular o debate sobre o papel que a disciplina pode cumprir na compreensão dos processos de ensino, por meio dos temas clássicos que giram em torno da organização e desenvolvimento do ensino, de maneira situada e crítica, mas também por meio das novas temáticas, reveladoras das questões sociais e educativas relevantes nesse momento histórico, no país.

Diante da complexidade da temática, devem-se reconhecer os limites da pesquisa e apontar a necessidade de articular novas perguntas a serem respondidas em futuras investigações, principalmente no que se refere à tentativa de evidenciar a importância da disciplina de Didática e o seu reposicionamento na formação inicial e continuada de professores.

\section{Referências}

AGUAYO, A. M. Didática da escola nova. Tradução e notas: J. B. Damasco Penna e Antônio D’Ávila. 14. ed. São Paulo: Companhia Editora Nacional, (Atualidades Pedagógicas, v. 15). 1970.

ANDRÉ, M. Tendências da pesquisa e do conhecimento didático no início dos anos 2000. In: ENDIPE, XIV, 2008, Porto Alegre. Anais... Porto Alegre, 2008. p. 487-499. CD-ROM.

ANDRÉ, M.; CRUZ, G. B. A produção do conhecimento didático na RBEP (19982010). Revista Brasileira de Estudos Pedagógicos, Brasília, v. 93, n. 234 p [número especial], p. 443-462, mai./ago. 2012. 
BARDIN, L. Análise de conteúdo. Lisboa: Edições 70, 2009.

BOURDIEU, P. Razões práticas: sobre a teoria da ação. Campinas: Papirus, 1996.

BUFREM, L; SCHMIDT, M. A. e GARCIA, T. B. Os manuais destinados a professores como fontes para a história das formas de ensinar. Revista HISTEDBR On-line, Campinas, SP, $\mathrm{n}^{\circ}$ 22, p. 120-130, jun. 2006.

CANDAU, V. M. Didática questões: contemporâneas. Rio de Janeiro: Editora Forma \& Ação, 2009.

Didática e perspectiva multi/ intercultural: a produção dos ENDIPEs de 1994 a 2002. In: CANDAU, V. (Org.). Educação intercultural e cotidiano escolar. Rio de janeiro: 7 Letras, 2006, p.5273.

\section{Rumo a uma nova didática.}

Petrópolis : Vozes, 1993.

Vozes. 1984.

A didática em questão. Petrópolis:

CASTRO, A. D. A trajetória histórica da didática. Série Ideias, n. 11. São Paulo: FDE, 1991. p. 15-25. Disponível em<http://www. crmariocovas.sp.gov.br/pdf/ideias_11_ p015-025_c.pdf>. Acesso em: 08 mai. 2013.

CAstro, A. D.; CARVAlHO, A. M. P. (Org.). Ensinar a ensinar: didática para a escola fundamental e média. São Paulo: Pioneira Thomson Learning, 2001.

CHERVEL, A. História das disciplinas escolares: reflexões sobre um campo de pesquisa. Rev. Teoria e Educação, Porto Alegre, n.2, p.177-229, 1990.

CHOPPIN, A. "Pasado y presente de los manuales escolares”. Traducido por Miriam Soto Lucas. Revista Educación y Pedagogía. Medellín: Facultad de Educación. n. 29-30, p. 209-229, 2001.
CORREIA, A. C. Olhar a escola através dos livros de texto para formação de professores. In: SEMINÁRIO DE ESTUDOS NA FACULDADE DE EDUCAÇÃO DA UNIVERSIDADE DE SÃO PAULOFEUSP, 2000, São Paulo. Anais... São Paulo, 2000.

CUESTA FERNANDEZ, R. Clío en las aulas: la enseñanza de la historia en España entre reformas, ilusiones y rutinas. Madrid: Akal, 1998.

\section{Sociogénesis de una disciplina}

escolar: la historia. Barcelona: PomaresCorredor, 1997.

FARIAS, I. M. S. et al.. Didática e Docência: aprendendo a profissão. Brasília: Liber Livro, 2009.

FRANCO. M. L. P. B. Análise de Conteúdo. 2. ed. Brasília: Líber Livros, 2005.

FRANCO, M. A. S.; FUSARI, J. C. Apresentação. In: FRANCO, M. A. S.; PIMENTA, S. G. (Orgs.). Didática: embates contemporâneos. São Paulo: Edições Loyola, 2010.

GARCIA, T M. F. B. Do como ensinar ao como educar: elementos do código disciplinar da Didática Geral no manual de João Toledo (1930). In: VIII CONGRESSO LUSO-BRAS. DE HIST. DA EDUC, 2010, São Luís, MA. Anais... São Luís, MA: EDUFMA, 2010. v. 1. p. 1-16.

Esquemas de trabalho para o domínio dos conhecimentos: módulos instrucionais de didática geral para formar professores na década de 1980. In: VIII CONGRESO IBEROAMERICANO DE HISTORIA DE LA EDUCACIÓN LATINOAMERICANA, Buenos Aires, Argentina. Anais... Buenos Aires, Argentina: Sociedade Argentina de Historia de la Educación, 2007. p. 1-23. 
- Treinando habilidades para o ensino: perspectivas da Didática no início da década de 1970. In: ENCUENTRO INTERNACIONAL DE HISTORIA DE LA EDUCACIÓN "ENTRE LA MEMORIA Y EL OLVIDO, 10, 2006, México. Anais... Guanajuato, México, 2006. p. 1-10. CDROM

GARCIA, T. M. F. B; HEGETO, L. C. F. A didática geral como disciplina escolar: análise a partir de manuais didáticos. In: X EDUCERE/ I SIRSSE, 2011, Curitiba, PR. Anais... Curitiba: Champagnat, 2011. p. $1-11$.

GARCIA, T. M. F. B.; NASCIMENTO, F. E. A Didática e os Manuais para Ensinar a Ensinar Física. In: EDUCERE - III ENCONTRO SUL BRASILEIRO DE PSICOPEDAGOGIA, IX, 2009, Curitiba. Anais... Curitiba: Champagnat, 2009. p. 8634-8645.

GATTI, B. A. et al. Formação de professores para o Ensino Fundamental: instituições formadoras e seus currículos; relatório de pesquisa. 2v. São Paulo: Fundação Carlos Chagas; Fundação Vitor Civita, 2008.

GATTI, B. A.; NUNES, M. M. R. (Org.). Formação de professores para o Ensino Fundamental: estudo de currículos das licenciaturas em pedagogia, língua Portuguesa, Matemática e Ciências Biológicas. Textos FCC, São Paulo, v. 29, 2009. 155p.

GRISI, R. Didática mínima. São Paulo: Ed. do Brasil, 1952.

GUEREÑA, J. OSSENBACH, G. POZO, M. (Diretores). Manuales escolares en España, Portugal y América Latina (Siglos XIX e XX). Madrid: Universidad Nacional de Educación a Distancia - UNED, 2005.
HAYDT, R. C. C. Curso de didática geral. São Paulo: Ática. 1994.

HEGETO, L. C. F. A didática como disciplina escolar: estudo a partir dos manuais de Didática Geral, 2014. Tese (Doutorado em Educação) - Universidade Federal do Paraná, Curitiba, 2014.

HEGETO, L C. F. GARCIA, T. M. F. B Didática Geral: Os manuais como elementos visíveis do código disciplinar. In: GARCIA, T. B. et al. (Org.). Desafios para a superação das desigualdades sociais: o papel dos manuais didáticos e das mídias educativas. 1ed. Curitiba, PR: IARTEM; NPPD, UFPR, 2013, v. 1, p. 316-326.

LIBÂNEO, J. C. O ensino da didática, das metodologias específicas e dos conteúdos específicos do ensino fundamental nos currículos dos cursos de Pedagogia. In: Revista Brasileira de Estudos Pedagógicos - RBEP. Brasília, v. 91, n. 229, p.562-583, 2010.

MARIN, A. J. Didática e currículo: conceitos, pesquisa e necessidade de avanço. In: COLÓQUIO LUSO-BRASILEIRO SOBRE QUESTÕES CURRICULARES, 7, 2008, Florianópolis. Anais... Florianópolis, 2008.

MARIN, A. J; PENNA, M. G. O; RODRIGUES, A. C. C. A didática e a formação de Professores. Rev. Diálogo Educacional. PUC/PR. Curitiba, v. 12, n. 35, p. 51-77, jan./ abr. 2012.

MARTINS, P. L. O. Didática teórica. Didática prática: para além do confronto. São Paulo: Loyola, 1989.

MARTINS, P. L. O. \& ROMANOWSKI, J. P. A Didática na formação pedagógica de professores nas novas propostas para os cursos de licenciatura. In: DALBEN, A. I. L. de F. et al. (Orgs.). Convergências e tensões 
no campo da formação e do trabalho docente. Belo Horizonte: Autêntica, 2010.

MOURA, M. O. A atividade de ensino como ação formadora. In: CASTRO, A. D.; CARVALHO, A. M. P. (Orgs.) Ensinar a ensinar: didática para a escola fundamental e Média. São Paulo: Pioneira Thomson Learning, 2001.

NÓVOA, A. (Org.). Profissão professor. 2. ed. Porto: Porto Editora, 1995.

PEIXOTO, A. Ensinar a ensinar. Rio de Janeiro: Francisco Alves, 1930.

PETERS, O. Didática do ensino a distância: experiências e estágio da discussão numa visão internacional. Trad. Ilson Kayser. São Leopoldo: Editora Unisinos, 2006.

PILETTI, C. Didática geral. Rio de Janeiro: Zahar, 1982.

SCHMIDT, M. A. M. dos S. Manuais de didática da história destinados à formação de professores e a constituição do código disciplinar da história no Brasil: 1935-1952. História (São Paulo), Franca, v. 30, n. 2, p. 126-143, ago./dez. 2011.

SILVA, V. B. Os livros das normalistas: os manuais pedagógicos na história da formação dos professores no Brasil (19301971), Revista QUAESTIO, Sorocaba, São Paulo, v. 10, n. 1/2, p. 115-132, mai./nov. 2008.

SILVA, V. B. Saberes em viagem nos manuais pedagógicos: construções da escola em Portugal e no Brasil (1870-1970). In: 29a REUNIÃO ANUAL DA ANPED, 29, 2006, Caxambu. Anais... Caxambu, 2006

TOSI, M R. Didática geral: um olhar para o futuro. Campinas: Alínea. 1996.

URBAN, A. C. Didática da história: percursos de um código disciplinar no Brasil e na Espanha, 2009. Tese (Doutorado em Educação) - Universidade Federal do Paraná. Curitiba, 2009.

VEIGA, I. P. A. Por dentro da Didática: um retrato de três Pesquisas. In: ENDIPE, XV, 2010, Belo Horizonte. Anais... Belo Horizonte: Autêntica, 2010.

VEIGA, I. P. A. (Org.) Lições de didática. 2. ed. Campinas - São Paulo: Papirus, 2006. 